\title{
3 year survival rates did not differ between patients with Alzheimer's disease and those with dementia with Lewy bodies
}

Walker Z, Allen RL, Shergill S, et al. Three years survival in patients with a clinical diagnosis of dementia with Lewy bodies. Int J Geriatr Psychiatry 2000 Mar;15:267-73.

QUESTION: In patients with Alzheimer's disease (AD) and in those with dementia with Lewy bodies (DLB), do mortality rates and duration of illness differ?

\section{Design}

Inception cohort followed up for 3 years.

\section{Setting}

An old age psychiatry unit in the UK.

\section{Patients}

114 patients with a clinical diagnosis of $\mathrm{AD}$ using ICD-10 criteria or a diagnosis of DLB using McKeith and Byrne criteria. 8 patients (7\%) were lost to follow up.

\section{Assessment of prognostic factors}

Case notes of all patients were reviewed to determine the original diagnosis, and the dates of symptoms onset and first presentation to psychiatric services.

\section{Main outcome measures}

Mortality rate and duration of illness were determined by reviewing case notes, hospital files, and general practitioner records.

\section{Main results}

Of the 106 patients followed, 43 originally had a diagnosis of $\mathrm{AD}, 32$ had $\mathrm{DLB}, 30$ had a diagnosis of vascular dementia, and 1 was diagnosed with alcoholic dementia. At 3 years, 64 patients $(60 \%)$ had died. More patients died in the vascular dementia group (87\%) than in the DLB group (53\%) and the AD group (49\%) $(p<0.003)$. No difference existed in the mortality rate between DLB and AD patients. The mean survival time from first onset of symptoms until death was 5.5 years in the DLB group and 5.6 years in the $\mathrm{AD}$ group with no statistically significant difference between the groups. The mean survival time from presentation to psychiatric services until death was 3.5 years in the DLB group and 3.1 years in the $\mathrm{AD}$ group with no statistically significant difference between the groups.

\section{Conclusion}

The 3 year survival rate did not differ between patients with Alzheimer's disease and those with dementia with Lewy bodies.

\section{COMMENTARY}

Cortical DLB is a relatively common cause of dementia, possibly accounting for up to $20 \%$ of cases, and should no longer be regarded as an esoteric rarity. The clinical characteristics include fluctuating cognitive ability, prominent visual hallucinations, and movement disorders including parkinsonism. Does distinguishing DLB from other causes of dementia have any implications for the clinician, patient, or carer? Yes. Although Walker $e t$ al found no difference in the prognosis of DLB compared with $\mathrm{AD}$, there are other characteristics of DLB that render diagnosis imperative. The visual hallucinations may tempt unwary clinicians to prescribe antipsychotic medication. This is likely to make the movement disorder worse, increase the risk of falls, and increase mortality. ${ }^{1}$ Some evidence is emerging that these symptoms may be helped by cholinesterase inhibitors, but further evaluation of this is awaited.

For the patient, the fluctuating cognitive ability may be profound (I once saw a patient with DLB who alternated between doing the Times newspaper crossword and sitting in a semi-vegetative state). The opportunity to understand the basis of this may be welcome (provided the clinician wants to go down the road of discussing the diagnosis with the patient). Carers may find the constellation of symptoms, especially the hallucinations, bewildering and frightening, and again, a label and explanation may be helpful.

This study by Walker $e t$ al has other important messages. Firstly, in this sample at least, clinical diagnosis of DLB was as common as vascular dementia. Secondly, the median survival time after onset of symptoms was 5.3 years, underpinning the fact that this is a chronic disease that may have a major effect on carers and services as well as our patients. Any study that heightens awareness of this form of dementia and contributes to our understanding of the disease is welcome.

James Warner, MD, MRCP, MRCPsych Imperial College, London, UK

1 McKeith IG, Fairbairn AF, Perry RH, et al. Neuroleptic sensitivity in patients with senile dementia of Lewy body Type. BMJ 1992;305:673-8.
Source of funding: not stated.

For correspondence: Dr Z Walker, Mental Health Unit, St Margaret's Hospital, The Plain, Epping, Essex CM16 6TN, UK. Fax $+44(0) 1992$ 571089 . 